\title{
Bacterial Coated Fertilizer Induced Resistance Against Wheat Stripe Rust
}

\author{
Hasan Riaz ${ }^{1 *}$, Zulqurnain Khan'2, Syed Shahid Hussain Shah ${ }^{3}$, Muhammad Yasir Khurshid ${ }^{3}$, Muhammad Asif Ali
}

1 Institute of Plant Protection, MNS University of Agriculture Multan

2 Institute of Plant Breeding and Biotechnology, MNS University of Agriculture Multan

3 Research and Development, Specialty Fertilizer Business, Engro Fertilizers Pakistan

* Correspondence: h.riazz@gmail.com

Citation: Riaz, H.; Khan, Z.; Shah, S. S. H.; Khurshid, M. Y.; Ali, M. A. Bacterial coated fertilizer induced resistance against wheat stripe rust. Pakistan Journal of Biochemistry and Biotechnology, 2021, 2 (2), 97-106. https://doi.org/10.52700/pjbb.v2i2.52

Received: 31-08-2021

Accepted: 29-12-2021

Published: 31-12-2021
Abstract: Wheat is the second largest consumed cereal by humans after Rice and its high yield and production is very critical for ever increasing global population. The wheat crop is grown all over Pakistan and threatened by several limiting factors. Stripe rust, caused by Puccinia striiformis $\mathrm{f}$. sp. tritici, is the most destructive wheat pathogen and can reduce yield up to $70 \%$ in Pakistan. The present study aimed at exploring the role of Zabardast urea, a bacterial coated urea with zinc, in inducing resistance against wheat stripe rust. The study involved the collection and maintenance of stripe rust inoculum on Morroco cultivar which later used to inoculate seedlings of Akbar-2019 and Galaxy-2019 resistant and susceptible varieties with three different fertilizer levels viz. specialty fertilizer zabardast urea, plain urea with zinc and plain urea. The results demonstrated the positive role of bacterial coated urea with zinc and reduced the disease severity by $10 \%$ and $5 \%$ in susceptible and resistant cultivars, respectively, leaving resistant variety asymptomatic. The plain urea with zinc also decreased disease severity in susceptible variety Galaxy-2013 by 6\% in comparison with plain urea treatment underlying the role of zinc in combating stripe rust $(\mathrm{p}<0.01)$. Moreover, the plant height responded very strongly to the fertilizer treatments $(p<0.01)$ whereas SPAD chlorophyll value was influenced by varietal type $(\mathrm{p}<0.05)$ but non-significant behavior was observed in SPAD chlorophyll values with fertilizer treatments. The SOD activity was highly significant in case of fertilizers and varieties respectively $(\mathrm{p}<0.01)$ while significant SOD levels differences were observed in interaction of fertilizers and varieties $(p<0.05)$. The study underlines the importance of specialty fertilizers in inducing resistance against stripe rust in wheat and needs further experimentation exploring the mechanisms involved in disease resistance under field conditions.

Keywords: wheat stripe rust; Puccinia striiformis; specialty fertilizer; Zinc; Endophytic bacteria

\section{Introduction}

Global wheat consumption has increased due to the change in socio-economic conditions, ever expanding urbanization and people's preference towards wheat as a staple food in daily life. The increasing trend predicted to forecast $60 \%$ increase in wheat consumption by year 2050 but it faces numerous challenges which lessen the wheat yield like quality seed availability, decreasing water and arable land, efficient use of 
fertilizers, pathogens and insect pest pressure [3,9]. Wheat enjoys prominent status in agriculture of Pakistan with per capita consumption of $124 \mathrm{~kg}$ [11] and cultivated by approximately $80 \%$ farmers covering almost 9 million hectares of land [4]. One of the major pathogens infecting wheat globally is rust fungi (Puccinia spp.) and reported to cause up to $60 \%$ (leaf rust), $70 \%$ (stripe rust) and 100\% (stem rust) yield loss in wheat. Stripe rust is the major challenge to wheat crop in Pakistan because 5.8 million hectares wheat cultivated area is vulnerable to wheat stripe rust [2;4]. Endophytic bacteria mostly survive inside the roots of the plants in an ecological harmony without harming the host plants and proving beneficial for the plants against the onslaught of pathogens. The endophytic bacteria are being reported to act as biological control agents by suppressing the pathogens in various pathosystems [14] employing either directly regulating the genes [19] or increasing availability of essential nutrients [10]. Moreover, many bacterial species are testified as a potent biological control agent against rust fungi [9]. Zinc is a very vital micronutrient, a proven yield enhancer in wheat [1], which is a cofactor of several enzymes and interacts with structural proteins. It also plays important role in boosting plant immunity and "Zn finger" proteins regulate certain transcription factor which are crucial for plant defense mechanisms [5, 20]. The enzyme superoxide dismutase (SOD) functions as an antioxidant by catalyzing the conversion of superoxide radicals to hydrogen peroxide, which can subsequently be reduced to water by other antioxidant enzyme. They are essential for its defense against the toxicity produced by partially reduced metabolites, generated during the normal biological reduction of molecular oxygen [17]. It was assumed that the presence of consortia of bacteria in Zarbardast Urea may involve the endophytic nature of bacteria which is likely to be responsible for high SOD activity and impart bio-chemical resistance against the stripe rust of wheat, therefore, a study was carried out aimed at exploring the role of bacterial coated zinc over urea in imparting resistance against wheat stripe rust.

\section{Materials and Methods}

The study was conducted in the Institute of Plant Protection, MNS University of Agriculture Multan.

\subsection{Selection of Wheat Varieties}

The wheat cultivars Akbar-2019 and Galaxy-2013 were selected for being resistant and susceptible against wheat stripe rust respectively. The Morocco wheat cultivar was used to multiply the Puccinia striiformis f. sp. tritici inoculum under controlled conditions.

\subsection{Maintenance of Stripe rust culture}

The stripe rust inoculum was collected from different areas of Multan district and maintained at Plant Disease Diagnostic Lab, MNS University of Agriculture Multan as per protocol demonstrated by Yasmeen et al., [21]. 


\subsection{Fertilizer Application Levels}

The three fertilizer treatments were applied in large pots (13 inch diameter) viz. Zabardast Urea (Bacterial coated urea specialty fertilizer with zinc) @ 50kg/1000 tones, Plain urea with zinc sulphate @ 6kg/1000 tones and plain urea @ 75 kg/1000 tones [13].

\subsection{Inoculation of stripe rust on wheat varieties}

The 20 days old seedlings of wheat varieties Akbar-2019 and Galaxy-2013 were sprayed with stripe rust inoculum with a sprayer having fine nozzle. The inoculation was done with few modification as described by Kiani et al., [9].

\subsection{Disease Rating}

The disease rating was done according to the modified Cobb's scale described by Peterson et al., [18].

\subsection{SOD Activity Essay}

The total SOD activity (EC 1.15.1.1) was determined according to the method described by Paoletti et al., [16]. One gram (1g) of plant material was taken from each treatment and was immediately crushed in mortar. To the homogenate obtained, $2 \mathrm{ml}$ of potassium phosphate buffer solution containing $100 \mathrm{mM} \mathrm{NaKP} \mathrm{i,} \mathrm{pH} \mathrm{7.0;} \mathrm{0.3g} \mathrm{polyvi-}$ nyl-polypyrrolidone (PVPP) and $200 \mathrm{ml}$ of fluoride-phenyl-methyl-sulfonyl (PMSF). The mixture was vortexed and kept for $30 \mathrm{~min}$ in an ice bath. The solid material was concentrated, centrifuging at $1000 \mathrm{~g}$ for $10 \mathrm{~min}$ and the recovered supernatant was centrifuged again at $10,000 \mathrm{~g}$ for $20 \mathrm{~min}$. The entire extraction procedure was carried out at $4^{\circ} \mathrm{C}$. All samples were kept at $25^{\circ} \mathrm{C}$. To record the enzymatic activity, the change in absorbance at $560 \mathrm{~nm}$ was measured every $30 \mathrm{~s}$ for $5 \mathrm{~min}$ in a spectrophotometer. The method defines a SOD unit as the amount of enzyme that causes $50 \%$ of the maximum inhibition of NBT to formazan blue, expressing the activity of the extracts as SOD units per mg of protein. The determination of each extract was carried out in triplicate.

\subsection{Experimental Design and Statistical Analysis}

The experimental units were laid out in completely randomized design with two-factor factorial. The data was analyzed using ANOVA and means were compared using LSD test in statistix 8.1 software. Performance of fertilizer treatment was assessed by applying Principal Component Analysis (PCA) with the help of GGEBiplot ${ }^{\circledR}$.

\section{Results}

The disease resistance recorded from the experimental units showed the performance of zabardast urea $\left(\mathrm{T}_{1}\right)$, plain urea + zinc sulphate $\left(\mathrm{T}_{2}\right)$ and plain urea $\left(\mathrm{T}_{3}\right)$ respectively. In case of $T_{1}, 50$ and 0 disease severity (DS) percentage was recorded in Galaxy-2013 and Akbar-2019 with a genotype response of moderately susceptible (MS) to resistant (R). The DS percentage of 54 and 5 with a genotype response of MS and $R$ was observed in $T_{2}$ while T3 resulted in 60 and 5 percent DS with MS to $S$ genotype response in Galaxy-2013 and Akbar-2019 respectively (Table 1; Figure 1). 


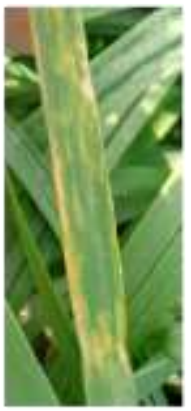

Zabardast Urea

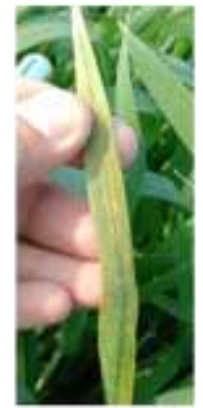

Plain Urea + ZS

Galaxy 2013

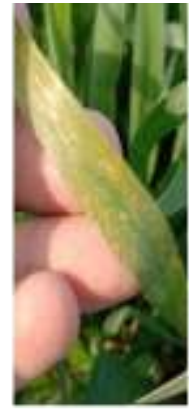

Plain Urea

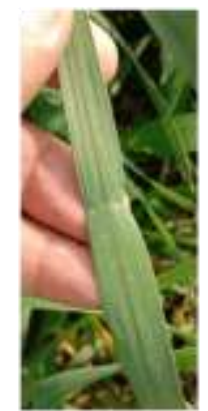

Zabardast

Urea

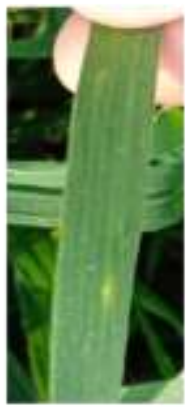

Plain Urea + ZS

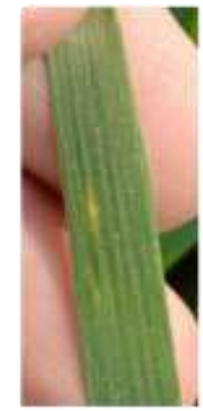

Plain Urea

Akbar 2019

Figure 1. Impact of fertilizers imparting resistance against wheat stripe rust

Table 1. Wheat stripe rust disease severity percentage susceptible (Galaxy-2013) and resistant (Akbar-2019) varieties

\begin{tabular}{|c|c|c|c|}
\hline & $\begin{array}{c}\text { Bacterial Coated Urea } \\
\qquad\left(T_{1}\right)\end{array}$ & $\begin{array}{c}\text { Plain Urea + Zinc } \\
\text { Sulphate }\left(\mathrm{T}_{2}\right)\end{array}$ & Plain Urea( $\left.\mathrm{T}_{3}\right)$ \\
\hline Galaxy-2013 & $50 \quad$ (MS) C & $54 \quad(\mathrm{MS}) \mathrm{D}$ & 60 (S) $\quad E$ \\
\hline Akbar-2019 & (O) $\mathbf{A}$ & (R) $\quad \mathrm{E}$ & (R) \\
\hline
\end{tabular}

Value in parenthesis connotes to resistance level

$\mathrm{MR}=$ Moderately Resistant; $\mathrm{MS}=$ Moderately susceptible; $\mathrm{S}=$ Susceptible; $\mathrm{O}=$ No disease symptoms; $\mathrm{R}=$ Resistant

Letters followed by parenthesis indicate the significant of means differentiated by LSD value $1.7887(\mathrm{P}<0.05)$

In terms of control, the zabardast urea $\left(\mathrm{T}_{1}\right)$ outperformed other fertilizers and induced 10 percent $\left(50 \%\right.$ DS) inhibition as compared to $\mathrm{T}_{2}$ and $\mathrm{T}_{3}(60 \%$ DS) in susceptible Galaxy-2013 cultivar. The $\mathrm{T}_{1}$ induced 5 percent resistance leading to $0 \% \mathrm{DS}$ as compared to other treatments (Table 1; Figure 2)

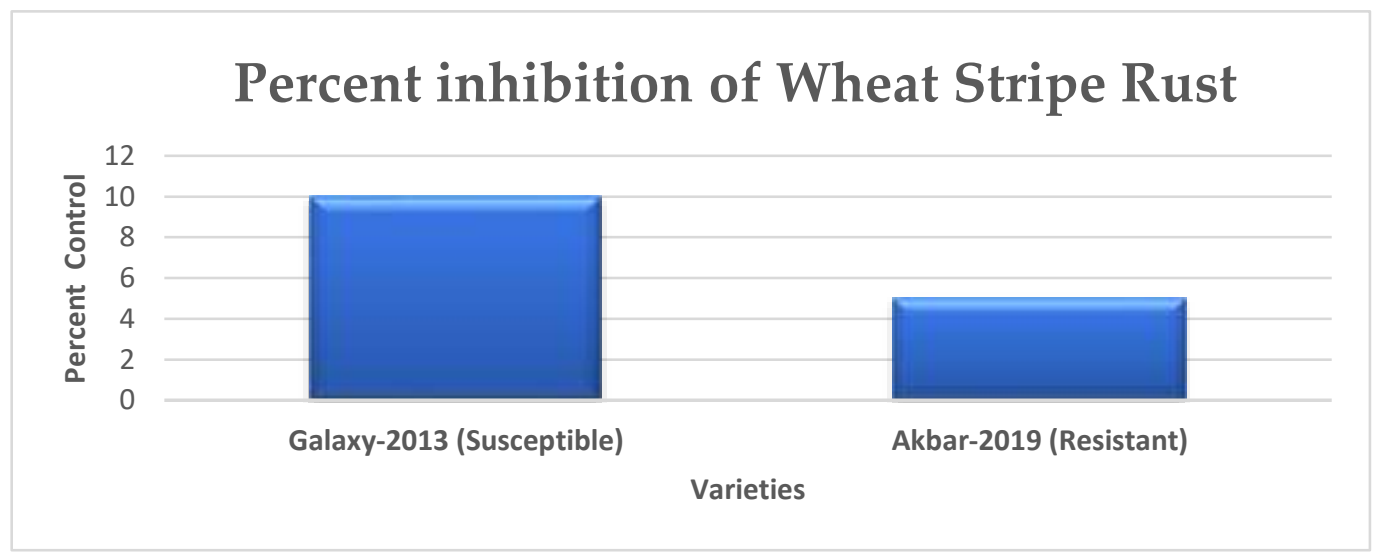

Figure 1. Inhibition of wheat stripe rust by Zarbardast urea

The statistical analysis revealed the high significant $\mathrm{P}$ values for fertilizers, varieties and their interactions. The varietal response were different confirming their genetically 
potential of Akbar-2019 to resist stripe rust and inability of Galaxy-2013 to restrict pathogen's growth. There have been highly significant differences $(\mathrm{p}<0.01)$ among the fertilizer treatments for plant height, whereas significant differences $(p<0.05)$ were observed among the varieties and their interaction with fertilizer treatments for plant height (Table 2). Although there were significant differences among the varieties for SPAD chlorophyll values but the non-significant differences among the fertilizers for SPAD resulted in non-significance of their interaction with the varieties. Highly significant differences for SOD activities among the fertilizers and varieties, and significant differences for their interaction were also observed (Figure 3).

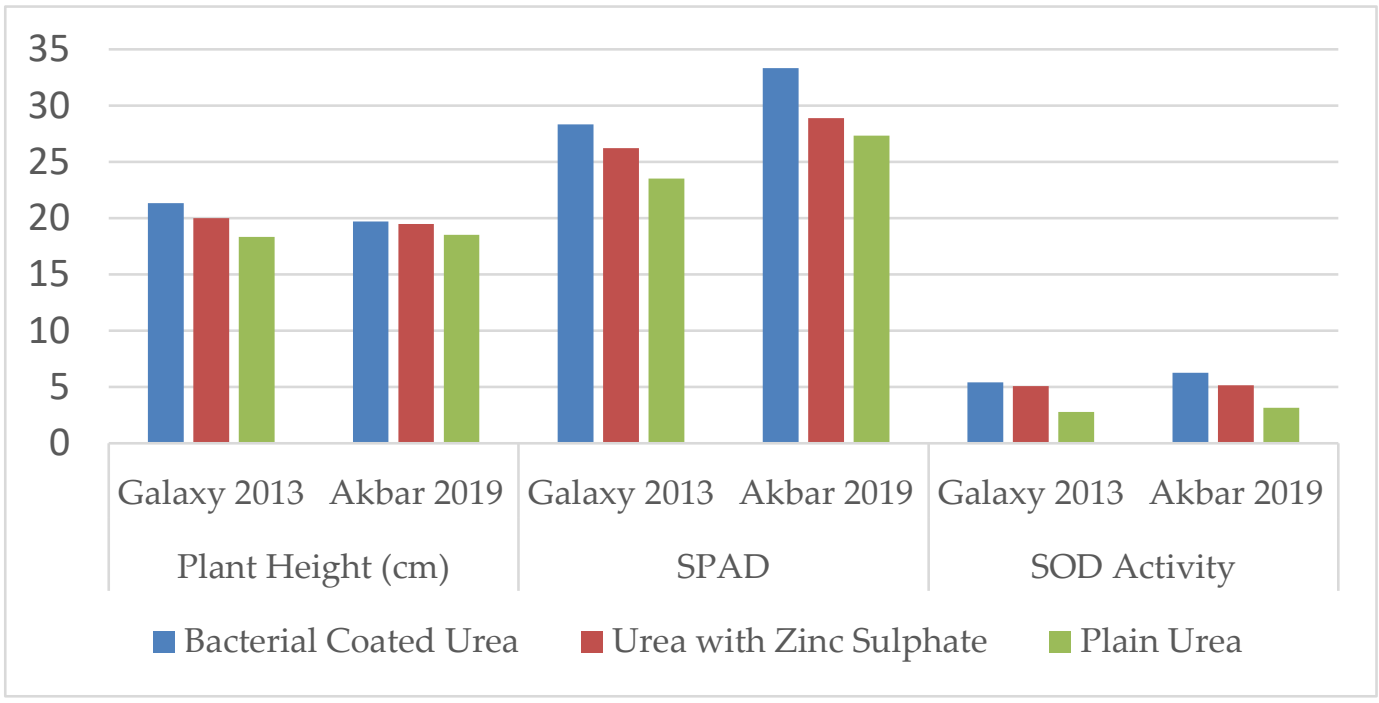

Figure 2. Parametric performance of Bacterial coated Zinc on urea with other fertilizers in wheat varieties

Table 2. P-value obtained from ANOVA

\begin{tabular}{llllc}
\hline \multicolumn{1}{c}{ Source } & $\begin{array}{c}\text { Disease } \\
\text { Severity }\end{array}$ & Plant Height & SPAD & $\begin{array}{c}\text { SOD } \\
\text { Activity }\end{array}$ \\
\hline Fertilizers & $0.0000^{* *}$ & $0.0001^{* *}$ & $0.1068 \mathrm{NS}$ & $0.0000^{* *}$ \\
Varieties & $0.0000^{* *}$ & $0.0241^{*}$ & $0.02840^{*}$ & $0.0007^{* *}$ \\
Fertilizers*Varieties & $0.0011^{* *}$ & $0.0345^{*}$ & $0.33309^{\mathrm{NS}}$ & $0.0175^{*}$ \\
& & & & \\
\hline
\end{tabular}

NS: Non-Significant; ${ }^{*}$ Significant at $5 \%$ probability level, ${ }^{* *}$ Significant at $1 \%$ probability level

Principle Component 1 (PC1) explained $97.6 \%$ whereas PC2 explained only $2.4 \%$ of the results. It is evident from the results that, for all fertilizers, disease severity (DS) is negatively correlated with SOD activity, plant height, and SPAD value. Higher SOD 
activity is desirable as observable in figure 4:4A pointing towards top right (positive side) marked with red line, contrary to the disease severity (bottom left) making the bacterial coated zinc on urea a desirable fertilizer. The SOD activity decreased (figure 4:4B) but the disease severity also increased more than that observed in bacterial coated zinc on urea. Disease severity increased and SOD activity decreased in the plants fertilized with the plain urea, marked with red line pointing towards left (figure 4:4C). Plant height $(\mathrm{cm})$, SPAD, and SOD activity were positively related with each other, but the degree of association with plant height and SPAD was more than that of present between SPAD and SOD; and SPAD and plant height. Negative association between disease severity and plant and SPAD was observed (Figure 5).
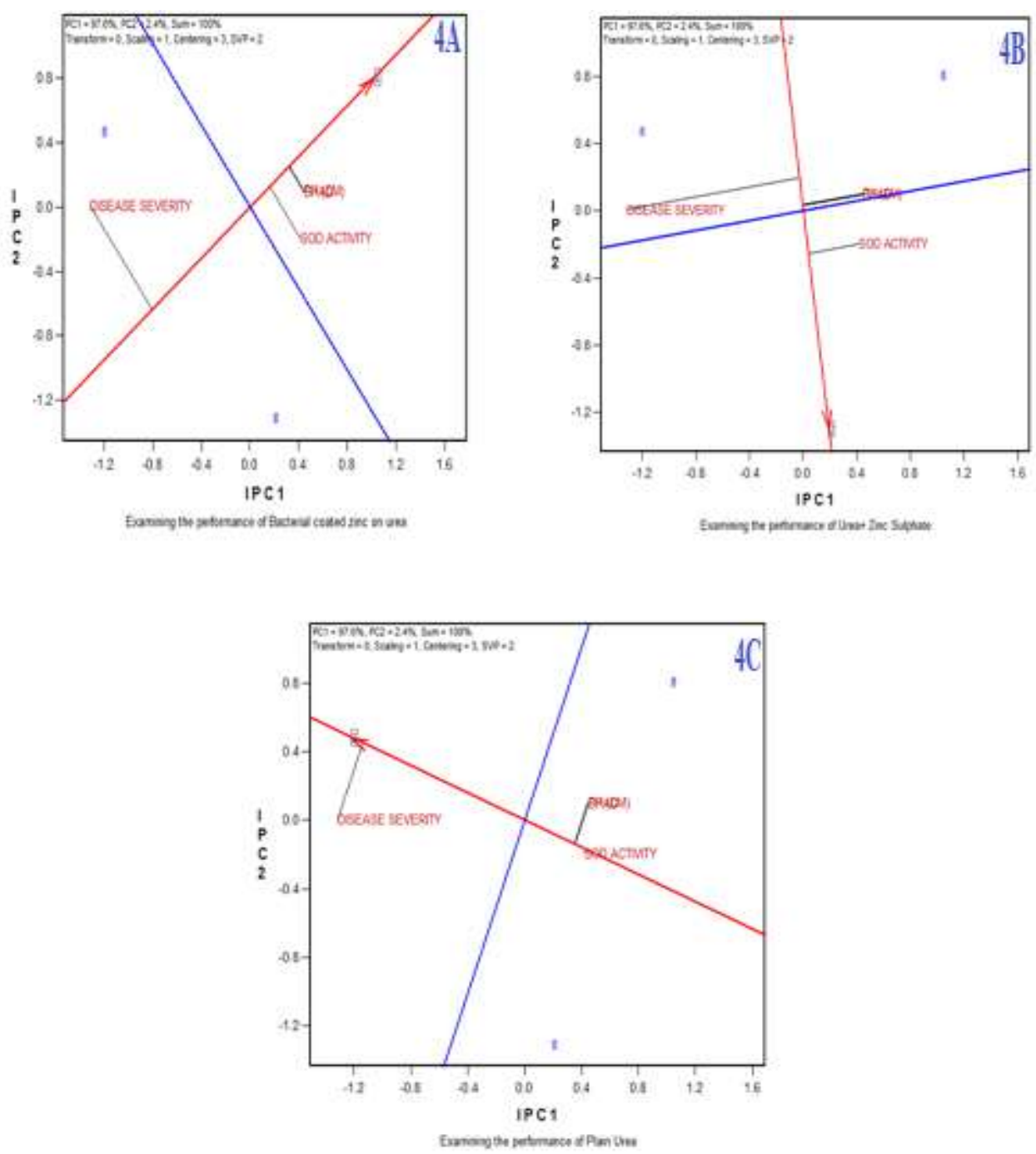

Figure 3. Principal Component Analysis (PCA); 4A: Performance of Bacterial coated zinc on urea; 4B: Performance of plain urea + zinc sulphate; 4C: Performance of plain urea 


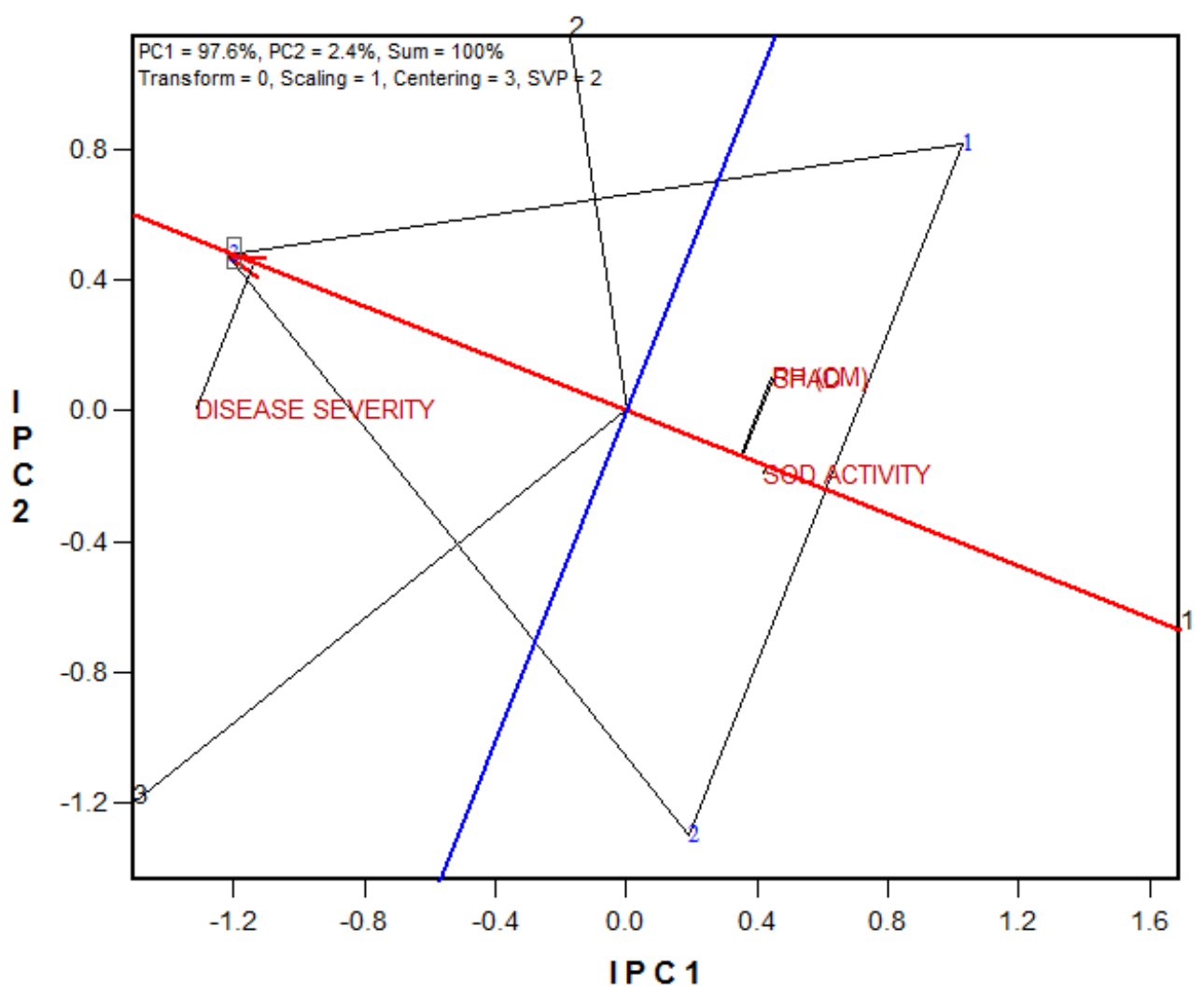

Performance of All fertilizer Treatments

Figure 4. PCA: Performance of all treatments (fertilizers)

\section{Discussion}

In present study, a specialty fertilizer by Engro fertilizer was tested for incorporating resistance in wheat against stripe rust caused by Puccinia striiformis f. sp. tritici. The Zabardust urea (bacterial coated with zinc) and plain urea+zinc sulphate induced resistance in susceptible cultivar Galaxy-2013 and reduced disease severity by $10 \%$ and $6 \%$ respectively when compared with plain urea application. The performance of Zabardast urea also impacted the disease severity in resistant cultivar Akbar-2019 resulting in asymptomatic plants with zero percent disease severity.

Increased level of SOD is the indicators of activated plant defense mechanisms. Although the diseases severity on plant fertilized with zinc sulphate and urea was almost similar with the plants fertilized with plain urea in naturally resistant cultivar Akbar 2019, the high SOD values in zinc fertilized plants indicate the competitive advantage for the forthcoming crop stages. As one of the most recognized functions of $\mathrm{Zn}$ is related to its impact on the correct functioning and structural stability of many proteins [5], where about $10 \%$ of them need this element (approximately 2,800 proteins) to develop regulatory, catalytic and structural actions. Therefore, the structural and functional integrity of biological membranes depends on a sufficient amount of $\mathrm{Zn}$ content. Genetic resistance fully expressed, under provided conditions, with the 
fertilization of zinc coated with bacteria on urea, hinting towards higher zinc uptake and higher SOD values advocate for the endophytic activity of coated bacteria on zarbardast urea, which activates the enzymes of self-defense against the biotic stresses including the incidence of rust [17].

The SOD activity remained the strongest indicator of efficacy of fertilizer activity as it weighted maximum in explaining principal components. It is observable from figure 5 that performance of all three fertilizer treatments on PCA matrix is expressed as triangular shape with two corners in positive right side and one corner in negative side indicating fertilizer 3 (urea) has maximum disease severity. The remaining two zinc containing fertilizers remain on positive right axis, indicating better performance than that of urea. Although both zinc containing fertilizers performed better than solo urea, the zinc in the form of zinc sulphate had negative value on PC2 whereas the zinc coated with bacteria had both principal components in positive axis, indicating supremacy of bacterial presence over normal zinc sulphate.

The study has three aspects which needs to be considered in assessing the reasons of disease resistance induction in wheat. First one is the association of coated bacteria with wheat roots which could be endophytic or ectophytic in nature as several studies indicated the role of endophytic bacteria in improving plant immunity and inducing rust resistance in wheat and other crops $[9,12,15,19]$. The second possibility is the role of zinc in systemic induced resistance against biotic stresses particularly fungal pathogens $[6,5,7,8,20,17]$. The third possibility which is quite evident from the results that coated bacteria has a significant role directly or indirectly by providing timely availability of zinc to wheat plants leading to increased resistance as compared to zinc application without bacterial coating. This is the first report of any specialty fertilizer mediated induced resistance against stripe rust of wheat.

\section{Conclusions}

The use of specialty fertilizer manufactured by Engro fertilizers, is a new sphere in crop production sciences and has an enormous potential in precision agriculture driven technologies. The present study has opened a novel domain of disease resistance induction through specialty fertilizer application and warrant the need to explore the mechanism underlying disease resistance through exploring the specialty fertilizer mediated identification and expression of genes through transcription analysis followed by quantitative PCR validation, endophytic nature of coated bacterium aided molecular identification techniques, identification of pathogen's growth patterns by electron microscopy and zinc bio-availability under field conditions.

Author Contributions: Hasan Riaz executed the experiments. Hasan Riaz and Muhammad Yasir Khurshid designed and wrote the manuscript. Zulqurnain Khan, Syed Shahid Hussain Shah and Muhammad Asif Ali provided technical support and reviewed the manuscript.

Funding: This research received no external funding.

Acknowledgments: The authors acknowledge the help provided by the technical staff in the Institute of Plant Protection, MNS University of Agriculture Multan. 
Conflicts of Interest: The authors declare no conflict of interest.

\section{References}

1. Ali, M. A., Naeem, F., Tariq, N., Ahmad, I., \& Imran, A. Bioactive Nutrient Fortified Fertilizer (BNFF); a novel hybrid approach for the enrichment of wheat grain with Zinc. Frontiers in Plant Science, 2870.

2. Arain, S., Sial, M. A., Laghari, K. A., \& Jamali, K. D. (2017). Screening for resistance against rust diseases in advanced wheat (Triticum Aestivum L.) genotypes. Adv Plants Agric Res, 7(1), 235-239.

3. Balfourier, F., Bouchet, S., Robert, S., De Oliveira, R., Rimbert, H., Kitt, J., \& Breed Wheat Consortium. (2019). Worldwide phylogeography and history of wheat genetic diversity. Science advances, 5(5), eaav0536.

4. Bux, H., Rasheed, A., Siyal, M. A., Kazi, A. G., Napar, A. A., \& Mujeeb-Kazi, A. (2012). An overview of stripe rust of wheat (Puccinia striiformis f. sp. tritici) in Pakistan. Archives of Phytopathology and Plant Protection, 45(19), 2278-2289.

5. Cabot, C., Martos, S., Llugany, M., Gallego, B., Tolrà, R., \& Poschenrieder, C. (2019). A role for zinc in plant defense against pathogens and herbivores. Frontiers in Plant Science, 10, 1171.

6. Dordas, C. (2008). Role of nutrients in controlling plant diseases in sustainable agriculture. A review. Agron. Sust. Develop. 28, 33-46.

7. Gupta, S. K., Rai, A. K., Kanwar, S. S., \& Sharma, T. R. (2012). Comparative analysis of zinc finger proteins involved in plant disease resistance. PLoS One 7, e42578.

8. Hojyo, S., \& Fukada, T. (2016). Roles of zinc signaling in the immune system. Journal of immunology research, 2016.

9. Kiani, T., Mehboob, F., Hyder, M. Z., Zainy, Z., Xu, L., Huang, L., \& Farrakh, S. (2021). Control of stripe rust of wheat using indigenous endophytic bacteria at seedling and adult plant stage. Scientific Reports, 11(1), 1-14.

10. Mari, M., Guizzardi, M., \& Pratella, G. C. (1996). Biological control of gray mold in pears by antagonistic bacteria. Biological control, 7(1), 30-37.

11. Manzoor, A., Maan, A. A., Khan, I. A., \& Shahbaz, B. (2021). A Mixed-Method Study To Enhance Food Security By Reducing Post-Harvest Wheat Losses In Punjab, Pakistan. Humanities, (2), 87-99.

12. Martínez-Hidalgo, P., García, J. M., \& Pozo, M. J. (2015). Induced systemic resistance against Botrytis cinerea by Micromonospora strains isolated from root nodules. Frontiers in Microbiology, 6, 922.

13. McGee, W. J. (1911). Soil erosion (No. 71). US Government Printing Office.

14. Narisawa, K., Tokumasu, S., \& Hashiba, T. (1998). Suppression of clubroot formation in Chinese cabbage by the root endophytic fungus, Heteroconium chaetospira. Plant pathology, 47(2), 206-210.

15. Pang, F., Wang, T., Zhao, C., Tao, A., Yu, Z., Huang, S., \& Yu, G. (2016). Novel bacterial endophytes isolated from winter wheat plants as biocontrol agent against stripe rust of wheat. BioControl, 61(2), 207-219.

16. Paoletti, F., Aldinucci, D., Mocali, A., \& Caparrini, A. (1986). A sensitive spectrophotometric method for the determination of superoxide dismutase activity in tissue extracts. Analytical biochemistry, 154(2), 536-541.

17. Passari, A. K., Leo, V. V., Singh, G., Samanta, L., Ram, H., Siddaiah, C. N., Hashem, A., Al-Arjani, A. F., Alqarawi, A. A., Abd_Allah, E. F., \& Singh B. P. 2020. In Vivo Studies of Inoculated Plants and In VitroStudies Utilizing Methanolic Extracts of Endophytic Streptomycessp. Strain DBT34 Obtained fromMirabilis jalapaL. Exhibit ROS-Scavenging andOther Bioactive Properties. Int. J. Mol. Sci, 21:7364.

18. Peterson, R. F., Campbell, A. B., \& Hannah, A. E. (1948). A diagrammatic scale for estimating rust intensity on leaves and stems of cereals. Canadian journal of research, 26(5), 496-500. 
19. Shiomi, H. F., Silva, H. S. A., Melo, I. S. D., Nunes, F. V., \& Bettiol, W. (2006). Bioprospecting endophytic bacteria for biological control of coffee leaf rust. Scientia Agricola, 63, 32-39.

20. Sinclair, S. A., \& Krämer, U. (2012). The zinc homeostasis network of land plants. Biochimica et Biophysica Acta (BBA)-Molecular Cell Research, 1823(9), 1553-1567.

21. Yasmeen, F., Ghafoor, A., Bahadur, A., Fatima, H., Rana, T. M., \& Leghari, M. K. (2013). Screening of Pakistani wheat germplasm against stem rust and stripe rust under controlled conditions and occurrence of some algal species. Int. J. Phycol. Phycochem, 9(2), 101-110. 